\title{
Anatomy and physiology model making project: Assessing students' perceptions, learning gains and academic outcomes
}

\author{
Arlene V. Pamplona, Fatema T. Al-Saadi, Said A. Al-Ghenaimi \\ Oman College of Health Sciences, South Batinah Governorate, Ministry of Health, Sultanate of Oman
}

Received: August 16, 2018

DOI: $10.5430 /$ jnep.v9n2p53

\author{
Accepted: September 24, $2018 \quad$ Online Published: October 8, 2018 \\ URL: https://doi.org/10.5430/jnep.v9n2p53
}

\begin{abstract}
Background and objective: Student-originated projects as an innovative teaching approach in the laboratory classes play an important role in maximizing students' learning by allowing them to venture into independent inquiry, making their experience more meaningful. Anatomy and Physiology model making project as a form of innovative technique in teaching science is well implemented in all Nursing Institutes under the Ministry of Health in Oman, that forms part of the laboratory assessment of the course. It started three years ago, with its objective of reinforcing the knowledge in a more active learning environment. Since its implementation in 2013, there has been no baseline study conducted along this area and the over-all effectiveness of the project has not been assessed. This study was conducted to find out the learning gains of nursing student in Anatomy and Physiology Laboratory Course through model-making project approach with the end view of formulating recommendations based on the tested findings.

Methods: The study employed descriptive correlational method of research and survey as the data gathering technique. The primary quantitative data came from purposively sampled Year I Bachelor of Science Nursing Student in Rustaq Nursing Institute of Academic Year 2015-2016 ( $\mathrm{n}=33$ ), and students' final course grades in Anatomy and Physiology as secondary data. The data obtained were treated using percentage, ranking, weighted mean, Chi-square test and correlation analysis.

Results: Findings revealed that the respondents strongly agreed to the learning gains obtained through the use of the modelmaking project in terms of skills and values domain (composite mean $=4.07 ; 4.43$ ) respectively, while agreed on the aspect of knowledge and attitude domains. The Chi-Square test values and correlation analysis showed significant relationship $(p=.000)$ between the profile of the respondents in terms of age and gender and their assessments on the learning gains, as well as on the correlation between perceived learning gains and grades of the students.

Conclusions: There were positive learning gains through the model-making project in terms of the four learning domains. Significant relationship were found between the profile of the respondents and their assessments of the learning gains. Furthermore, the perceived learning gains was significantly correlated with the grades of students in Anatomy and Physiology course. The formulated recommendations for the instructional guidelines were based on the lowest rated items and needed to be enhanced among the students.
\end{abstract}

Key Words: Student-originated project, Problem-based learning, Learning domains, Model-making project

\footnotetext{
${ }^{*}$ Correspondence: Arlene V. Pamplona; Email: avp1524@yahoo.com; Address: Oman College of Health Sciences, South Batinah Governorate, Ministry of Health, Sultanate of Oman.
} 


\section{INTRODUCTION}

Education has a significant impact on the knowledge and competencies of the nurse clinician as it does for all health care providers. ${ }^{[1]}$ The Ministry of Health $(\mathrm{MOH})$ of the Sultanate of Oman through their Nursing Institutes as its educational arm is faced with many challenges in its pursuit to provide quality health care education that is at par with the worldwide standard. Challenges from the list of education sector is the aim to provide qualified, well trained, skillful and globally competitive nursing graduates that can perform not only the required standard health services to the public but can also offer passionate care for the patient. Thus, as the face of nursing education is evolving and changing internationally, improving the quality and standard of nursing curriculum is deemed necessary. ${ }^{[2]}$

In line with the goal in addressing the worldwide emphasis and changes in nursing education, $\mathrm{MOH}$ as represented by all Nursing Institutes in Oman has continuously reviewed and updated nursing curriculum to equip with the global advancement in nursing education and the requirement of the workforce market. ${ }^{[2]}$ All Nursing Institutes are on the process of moving into college and have been started offering Bachelor Degree in Nursing since Academic Year 2014-2015. In addition, innovation in teaching strategies like the use of student-centered learning approach is seen as one way of reform to face the challenges. But according to the written statement on the book entitled: "The Element: How Finding your Passion Changes Everything", "the fact is that given the challenges we face, education doesn't need to be reformed it needs to be transformed. The key to this transformation is not to standardize education, but to personalize it, to build achievement on discovering the individual talents of each child, to put students in an environment where they want to learn and where they can naturally discover their true passions". ${ }^{[3]}$

Learning from real life situation and its application as an example of student-centered learning approach is the usual goal of student-originated project, like in the case of Anatomy \& Physiology model making project. This teaching-learning approach emerged more than half a century ago as an innovative teaching strategy commonly applied not only in the field of medicine, but also in other disciplines like engineering and economics. ${ }^{[4]}$ Through this method, students are challenged to work on valuable projects or even do simulations that mimic real life scenarios, maximizing their potentials and utilizing their in-born creativity. Projects tend to be more open-ended than problem-based learning, giving students more choice when it comes to demonstrating what they know. ${ }^{[4]}$ Thus, working on a student-originated project is a teaching approach that engages students in sustained, collaborative and real-world situations. ${ }^{[5]}$

On the other hand, Hye-Jung Lee $1 \&$ Cheolil, ${ }^{[6]}$ described project-based learning as one form of "social loafing" which is a negative aspect of collaborative learning. As further described by the authors, "social loafing include insufficient performances by some team members as well as a lowering of expected standards of performance by the group as a whole to maintain congeniality amongst members". These authors also mentioned that because teachers tend to grade the finished product only, the social dynamics of the assignment may escape the teacher's notice. Considering this point, these authors suggested that this aspect mandates proper monitoring and assessment, and if proven correct, it requires proper action, revisions and recommendations that needs to be addressed as soon as possible.

In the conduct of using model-making project as an innovative form of teaching and learning that can uplift the level of students' knowledge, Gage and Berliner, ${ }^{[7]}$ found that students who study models before a lecture may recall as much as $57 \%$ more on questions concerning conceptual information than students who receive instruction without the advantages of seeing and discussing models. Thus, model making as a form of student originated project in Anatomy and Physiology in laboratory classes, provides student with opportunities for a student-originated projects where student plan and set up individual or group projects of their own design, collect data and be creative inborn scientist. Therefore, it is an important move to assess how really this method of teaching science subject with laboratory can provide a lasting impression of how cooperative science might work. ${ }^{[8]}$

Anatomy and Physiology model making project as a form of innovative technique in teaching science subject is well implemented in all Nursing Institute under the Ministry of Health, and forms part of the laboratory exercise assessment of the course that accounts for five percent of the total continuous assessment grade of the student. It started three years ago, with its objective of reinforcing Anatomy and Physiology knowledge in more innovative and active learning environment. The students are grouped into 4-5 students according to the teacher's preference and instructed to prepare models on various anatomy and physiological structures of the organs involved in the course content using any one of the type of models like interactive models, working models or animated power point presentation that will be displayed or presented in one whole day culminating activity known as Open Day. The activity along with the model is evaluated based on clarity of the concept, organization of the content, originality, creativity, tidiness and punctuality with one percent weight in each category, gaining a total of five percent 
full mark.

Cognizant that the model making as a form of student originated project in Anatomy and Physiology laboratory among $\mathrm{MOH}$ Nursing Institutes is still in its infancy stage as a form of assessment, therefore, it is important to know how effective it is as an innovative teaching strategy. Furthermore, to address the current demands and goal of the educational system, this study proposed suggestions, recommendations, enhancement and guidelines on the conduct of the student originated project. It sheds light on the perceptions of the students as regards to their learning gains and academic outcomes on model making project. Moreover, findings from this study will be of great help to the curriculum committee to formulate a more effective tool in assessing students' performance related to student-originated project aligned to the course requirement of bachelor degree program in Nursing.

\section{Research questions}

Specific research questions addressed were as follows:

- What is the extent of perceived learning gains of students in the following learning domains: knowledge, skills, attitudes and values, relative to model making experience?

- Is there a relationship between the perceived learning gains and the student's final grades in Anatomy and Physiology?

- Is there a significant difference in the perceived level of attainment of learning gains when respondents are grouped according to age and gender, in model-making project?

\section{MethodS}

\subsection{Design}

This study made use of the descriptive method of research that evaluated through self-assessment the learning gains of students from student-originated projects related to the body system.

\subsection{Sample}

Purposively sampled respondents were Year I Bachelor of Nursing Students, last Academic Year 2015-2016. A total enumeration of 33 sampled respondents participated in the survey.

\subsection{Setting}

The study was conducted at Rustaq Nursing Institute as one representative institute under the Ministry of Health in Oman who implemented the use of model-making project as part of continuous assessment in the laboratory course of Anatomy and Physiology that started from Academic Year 2013-2014.

\subsection{Data collection}

The study used a researcher-made survey questionnaire that has been pilot tested and validated. The pilot study was carried out on four (4) Bachelor Nursing Year I Student of Rustaq Nursing Institutes approximately more than 10 percent of the total respondents and two (2) faculty members who are expert on the field of anatomy and physiology. Male and female students were included in the pilot study. Modifications were made on the questionnaire after the pilot testing based on the pilot study findings and reports of expert faculty.The questionnaire used was divided into section 1, 2, 3, 4 learning domains-knowledge, skills, attitude and values in a 5-point likert-type scale to measure students' perceptions on model-making project. The researcher personally handed the questionnaire for distribution to the respondents a day after their anatomy open day as primary data. Each questionnaire was attached with consent form for voluntary participation of the subjects. In addition, participants' information sheet was also attached that gives them detailed information about the study, how the data will be handled and how they can approach the researcher if they have concerns. All researchers were there to address any doubt or inquiry as regards the questionnaire, to retrieve them and to ensure a high respondent rate. The respondent rate was 100 percent. Copy of secondary data which is the final grade of the students in Anatomy and Physiology I came from institute grade files through the coordinator of academics and admin solicited from the letter of request addressed to the dean with attached consent of the respondents and was handed to the researchers at the end of the first semester Academic Year 2015-2016.

\subsection{Data analysis}

Both primary and secondary quantitative data were statistically interpreted to come up with the findings and results of the study. The data obtained were treated using percentage, ranking, weighted mean and Chi-square test to identify the extent of the learning gains and to determine the significant difference in the perceived level of attainment of learning gains based on demographic data. Correlation analysis using Pearson Correlation Coefficient was done to show the relationship between the perceived learning gain and the students' final course grades.

\subsection{Ethical consideration}

The study was approved by the Research Ethical Review and Approval Committee (RERAC) of the Ministry of Health in Oman- (Ref. DG/A/ 4418/2015/ PROPOSAL APPROVAL 14/12/2015). In the study, informed consents were sought before the actual participation. Participants' information sheet was attached to the informed consent. It emphasized the volunteer participation of each respondent and that they 
have the right to decline from participation or to withdraw at any time. In the consent form, the students were consented to grant permission to access their grades for the purpose of this study. They were assured that their scores will be aggregated and no names or unique identifiers will be disclosed in the publication. The study includes no harm for the subject dignity, rights, and safety. The respondents' identities were kept confidential as questionnaires were left anonymous as it had no name. After data collection and retrieval, the data gathered were kept safely in one specified computer owned by the researcher and the data were shared only between the 3 researchers. The data file was kept for further analysis until the study was completed.

\section{RESULTS}

The following are the data about the profile of the respondents who participated in this study, their assessment on their learning gains thru model-making project in terms of four learning domains, as well as the data about the relationship in terms of respondents profile and assessment of learning gains and the perceived learning gains and final course grades in Anatomy and Physiology.

Table 1 presents the profile of the respondents. The data on the gender of the respondents showed that there were more females than males among them. The majority of the respondents were already on their legal age. Demographic data also showed considerably large portion of the respondents have experienced doing student - originated project more than twice, during their secondary school and foundation courses.

Table 2 shows that the respondents agreed that they had learning gains from model-making projects as to knowledge domain. The highest among the indicators of the learning gains as to knowledge borne out of the use of the modelmaking project was the item on it was able to help them analyze related processes and information with a weighted mean of 4.22 .

Table 1. Profile of the respondents and experience on student-originated project

\begin{tabular}{llllllllll}
\hline Gender & Freq. & $\mathbf{\%}$ & Age & Freq. & $\mathbf{\%}$ & Experience on student-originated project & Freq. & \% \\
\hline Male & 6 & 18 & $18-19$ & 16 & 48.8 & Once & 8 & 24 \\
Female & 27 & 82 & $20-21$ & 17 & 51.52 & More than twice & 25 & 76 \\
Total & 33 & 100 & & 33 & 100 & & 33 & 100 \\
\hline
\end{tabular}

Table 2. Assessment of the respondents on their learning gains thru model-making project in terms of knowledge domain

\begin{tabular}{lllc}
\hline Indicators & Weighted Mean & Verbal Interpretation & Rank \\
\hline The project... & & & 3 \\
1 reinforced my knowledge in Biology. & 3.96 & Agree & 5 \\
2 stimulated my understanding of related processes principles. & 3.76 & Agree & 4 \\
3 helped me read and understand primary literature. & 3.80 & Agree & 1 \\
4 helped me analyze related processes and information. & 4.22 & Strongly Agree & 2 \\
5 helped me understand and critically related information. & 4.12 & Strongly Agree & Agree \\
Composite Mean & 3.97 & & \\
\hline
\end{tabular}

As shown in Table 3, the respondents strongly agreed they had learning gains through model-making in terms of skills domain. In terms of the highest item rated, it was on that they were helped by model-making projects to conceptualize and build appropriate model. This obtained a weighted mean of 4.38 and was further verbally interpreted as strongly agree. Mostly, the respondents strongly agreed on their ability to conceptualize and build the appropriate model of the concept they were to build or do because of these model-making projects. With this also, the respondents strongly agreed that with the use of the model-making projects, they were able to enhance their skills domain.

Table 4 shows that the respondents agreed on the learning gains they achieved thru model-making project in terms of attitude domain. As to the highest item which obtained a weighted mean of 4.24 said that the model-making project, enticed the respondents to collaborate with their classmates. Hence, it could be gleaned that the respondents believed that they had learning gains thru the use of model-making projects as to their attitude domain.

As shown in Table 5, the respondents strongly agreed to the learning gains obtained by the use of the model-making projects to help them have learning gains in Human Anatomy. With this, the highest from among the indicators in terms of values domain showed that the respondents assessed that they were transformed to have a concern for life and life 
forms with a weighted mean of 4.70 . This meant that they strongly believed that they gained this learning in terms of values domain with the use of the model-making projects.

Table 6 shows that there was a significant relationship between the profile of the respondents in terms of age and gender and their assessments on the learning gains through model-making as to knowledge, skills, attitudes, and values domains. The Chi-Square test values showed significant relationship valued at .000 which was lower than the critical value of .05 .

Hence, it showed that there was a significant relationship that existed between the profile and the assessment on the learning gains. Then, the formulated research question no. 3 as an interrogatively statement for null hypothesis was rejected.

Table 3. Assessment of the respondents on their learning gains thru model-making projects in terms of skills domain

\begin{tabular}{|c|c|c|c|}
\hline Indicators & Weighted Mean & Verbal Interpretation & Rank \\
\hline \multicolumn{4}{|l|}{ The project... } \\
\hline 1 helped me conceptualize and build an appropriate model & 4.38 & Strongly Agree & 1 \\
\hline 2 helped me come up and present a model of a concept & 4.04 & Strongly Agree & 3 \\
\hline 3 permitted me to offer explanations for their findings to be understood & 3.80 & Agree & 5 \\
\hline 4 allowed me to discuss and synthesize information using the model & 4.00 & Strongly Agree & 4 \\
\hline 5 made me translate the gained knowledge and skills into practice & 4.16 & Strongly Agree & 2 \\
\hline Composite Mean & 4.07 & Strongly Agree & \\
\hline
\end{tabular}

Table 4. Assessment of the respondents on their learning gains thru model-making projects in terms of attitude domain

\begin{tabular}{llll}
\hline Indicators & Weighted Mean & Verbal Interpretation & Rank \\
\hline The project... & & & Agree \\
1 stimulated my interest in Biology & 3.96 & Strongly Agree \\
2 developed in me appreciation of the subject matter & 4.04 & Agree & 3 \\
3 developed in me appreciation of modern scope of scientific inquiry & 3.72 & Strongly Agree & 5 \\
4 increased my confidence in conducting scientific investigations & 4.06 & 4.24 & Strongly Agree \\
5 enticed me to collaborate with my classmates & 4.00 & Agree & 1 \\
Composite Mean & & \\
\hline
\end{tabular}

Table 5. Assessment of the respondents on their learning gains thru model-making projects in terms of values domain

\begin{tabular}{lllc}
\hline Indicators & Weighted Mean & Verbal Interpretation & Rank \\
\hline The project... & & & \\
1 developed in me respect for life and all its form & 4.56 & Strongly Agree & 2 \\
2 developed in me adaptability while working with my group & 4.36 & Strongly Agree & 4 \\
3 made me realize the variety of ways that an organism operates & 4.12 & Strongly Agree & 5 \\
4 developed in me responsibility to care for my body & 4.44 & Strongly Agree & 3 \\
5 transformed me to have a concern for life and life forms & 4.70 & Strongly Agree & 1 \\
Composite Mean & 4.43 & Strongly Agree & \\
\hline
\end{tabular}

Table 6. Relationship between the profile and the assessments of the respondents of their learning gains thru model-making project

\begin{tabular}{lllll}
\hline Profile & Chi-Square Test & & $\boldsymbol{p}$-Value & Verbal Interpretation \\
\hline Age & Knowledge & 125.74 & .000 & Significant \\
$17-18$ years old & Skills & 127.85 & .000 & Significant \\
$19-20$ years old & Attitude & 130.83 & .000 & Significant \\
& Values & 146.55 & .000 & Significant \\
Gender & Knowledge & 97.03 & .000 & Significant \\
Male & Skills & 90.67 & .000 & Significant \\
Female & Attitude & 94.27 & .000 & Significant \\
& Values & 109.49 & .000 & Significant \\
\hline
\end{tabular}


Table 7 shows the correlation between grades of students and their perceptions as regards their learning gains from the model making projects. All the $p$ values are lower than
.05. It can be concluded that there is significant positive relationship between the perceived learning gains and the grades of the students.

Table 7. Relationship of perceived learning gains and grades

\begin{tabular}{llll}
\hline Variables & Correlation Coefficient $\mathbf{r}$ & $\boldsymbol{p}$-Value & Verbal Interpretation \\
\hline Knowledge & 0.781 & .000 & Significant \\
Skills & 0.910 & .000 & Significant \\
Attitude & 0.967 & .000 & Significant \\
Values & 0.851 & .000 & Significant \\
\hline
\end{tabular}

\section{Discussions}

Based on the demographic profile of the respondents, as the common assignment of gender for students, females were supposed to dominate the profession compared to males. In addition, the finding implied that more female gender choose the nursing profession compared to male gender. This was due to the observable fact that females were mostly attracted to the nursing profession compared to males. It was likewise believed that the profession was meant for females much more for males. This finding also found that majority of the respondents are mature enough to carry out the objectives of the model-making project and that they were more responsible enough to finish the activity because of their cooperation and team work. The finding further implied that more of the respondents have gained necessary backgrounds in doing the project. This meant that majority of the respondents was already inclined with the nature of doing student-originated project.

In terms of knowledge domain based on the findings, the respondents were able to understand how processes and information related to the topics discussed in Anatomy were. The findings further implied that they saw clearly and comprehended the processes that happened in the topics discussed in the subject more than only discussion in the classroom and doing reading on their own and they believed that through the use of the model-making projects, they were able to realize the importance of knowing such processes and information. Moreover, with the use of the model-making project, the topics were made clearer to them because of the way they did the hands-on activities in model-making projects. The finding is supported by the study conducted by Ulseth et al., ${ }^{[9]}$ that team oriented project based learning focused on industry-contributed and industry-mentored design projects. The study further mentioned that, an innovative aspect of the program model is that student learning activities (both technical and professional) are centered around design project offered by external organizations. Moreover, these authors described that while working on the projects, students have ownership in the selection of their competencies and in the design of learning objectives as well as learning activities and had an increase in terms of the knowledge of the subject matter. With this, it was visible that the respondents had an increase in the knowledge of the topics discussed because of the model-making project that they were asked to do. Indeed, learning gains were evident to the students through the use of the model-making project in terms of the knowledge domain.

Findings related to skills domain suggest that the respondents were able to be helped by the model-making projects in terms of the conceptualization of the abstract concepts of the topics discussed. They were also able to visualize the abstract concepts thru the use of the models they built. This helped them a lot to better understand these abstract concepts due to seeing them using the model-making projects they built. As posited by Thomas, ${ }^{[10]}$ Project-based learning (PBL) is a model that organizes learning around projects. According to the definitions found in PBL handbooks for teachers, projects are complex tasks, based on challenging questions or problems, that involve students in design, problem-solving, decision making, or investigative activities; give students the opportunity to work relatively autonomously over extended periods of time; and culminate in realistic products or presentations. ${ }^{[11]}$ Hence, the findings on the ability of the students to increase their skills domain by using the model-making project are supported by the findings of the research conducted by scholars. In a way, the findings of the present study are supported by these existing related studies to testify to the soundness of the learning gains of the students with the use of this model-making project.

In terms of attitude domain, findings implied that, the modelmaking project helped them to work cooperatively and collaboratively with the members of their group. This positive attitude once again proved by the respondents as an important aspect in completing student-originated project so as they were able to do their model. It was also evident that this activity helped them to collaborate not only in the classroom, not only in the science subject but also to the real event of 
their everyday life. As found out by Gordon, ${ }^{[12]}$ projects are realistic, not school-like. According to him, "projects embody characteristics that give them a feeling of authenticity to students, which can include the topic, the tasks, the roles that students play, the context within which the work of the project is carried out, the collaborators who work with students on the project, the products that are produced, the audience for the project's products, or the criteria by which the products or performances are judged". "PBL incorporates real-life challenges where the focus is on authentic problems or questions and where solutions have the potential to be implemented". ${ }^{[13]}$ This made students collaborate and cooperate with each other. Hence, it could be seen that the model-making projects used by the teachers in helping students not only to learn but also to help each other finish the task was indeed very essential to the development of the attitude domains of the students themselves.

As shown from the response of the respondents in terms of values domain, model-making projects helped them to discover life and thus enabling them to respect and love all life forms. Unlike before, this time they believed that they already imbibed among themselves the respect and love for nature or the environment. The findings of the present study are supported by Savoei \& Hughes ${ }^{[14]}$ that results of their study were presented in terms of three measures of student learning: a design task that assesses how well students handle a new design problem, a measure of students' understanding of standards-based geometry concepts, and a measure of students' collaborative design proficiency. Hence, it was evident that with the use of the model-making project, the students were able to develop not only their cognitive and skill domains but their attitude and values domains as well. As a whole, the students were able to develop their totality or holistic development with the use of the model-making project.

The significant relationship that existed between the profile and the assessment on the learning gains was indeed evident with the findings that the age and gender of the respondents being mature students and mostly female that they found the model-making projects just within their level and skills. This helped them understand very much their activities as well as the topics and finally achieve learning gains for themselves. This finding was supported by Boaler, ${ }^{[15]}$ in her investigation of mathematics learning in two contrasting schools, found differences between girls and boys in their preferred mode of learning and in the extent to which they could adapt to different forms of instruction. Girls were found to be more disaffected by traditional instruction than boys and showed lower achievement than a matched sample of girls taught with project-based methods. Boaler suggested that girls seem to Published by Sciedu Press prefer being taught using methods that stress understanding vs. memorization and learning procedures. Boaler suggested further that exposure to project-based methods might raise the mathematical achievement of all students, especially girls. Thus, it was believed that the females who were exposed to model-making project tend to achieve better that those who did not. To deduce, the use of the model-making project helped the students, especially females, to achieve better than they did in the past.

In terms of the correlation between grades of students and their perceptions as regards their learning gains from the model making projects. It can be concluded that there is significant positive relationship between the perceived learning gains and the grades of the students. This connote that as their perceived learning gains in four learning domains increase, the same trend is evident with their grades.

\section{CONCLUSIONS AND RECOMMENDATIONS}

This study sheds light on the perceptions of the students as regards to their learning gains and academic outcomes on model making project. Based from the foregoing findings, it was concluded that the respondents were mostly on their legal age and were mature and responsible enough to conduct their own learning thru the use of the model-making projects. The use of the model-making project helped the students, especially females, to achieve better than they did in the past. There were positive gains in the learning of the students thru the model-making projects in terms of knowledge, skills, attitudes, and values. The respondents' profile was significantly related to their learning gains in terms of four learning domains. Furthermore, the perceived learning gains were significantly correlated with the grades of students in Anatomy and Physiology course.

Based on the findings of the study, a set of instructional guidelines were drafted for possible adoption by teachers employing model-making projects (see Table 8 ). The formulated recommendations for the instructional guidelines were based on the lowest rated items and needed to be enhanced among the students. They were believed to be not completely achieved by the respondents as they had to be focused by the teachers. With this, the students will be able to utilize the models of the projects to be able to achieve the learning gains to the fullest. Likewise, the aim of the recommendations given was towards instructional guidelines that will hopefully help all teachers concerned to maximize the use of the model-making projects as an assessment tool to measure the learning outcomes of Anatomy and Physiology laboratory course since they were found out to have an increase in the learning gains of the students as seen in their responses. 
Table 8. Instructional guidelines on model-making project

\begin{tabular}{ll}
\hline Indicators & Recommendations \\
\hline Knowledge Domain & $\begin{array}{l}\text { Use model-making project to stimulate the understanding of related processes principles. In doing this the } \\
\text { teacher should focus on the related processes principles of the topic. } \\
\text { The model-making project must help students to find explanations for their findings to be understood. In } \\
\text { doing this, the teacher must ask each student to explain how they are able to get to the findings thru their } \\
\text { model-making projects. } \\
\text { The model-making project must develop among the students the appreciation of modern scope of } \\
\text { scientific inquiry. In doing this, the teacher must be able to include in the process of the model-making } \\
\text { project something on the appreciation or discussion of the modern scope of the scientific inquiry. } \\
\text { The model-making project must make the students realize the variety of ways that an organism operates. } \\
\text { In doing this, the teacher must focus on the organism in the model making project and its ways of } \\
\text { Values Domain }\end{array}$ \\
\end{tabular}

\section{Limitations of the study}

Limitations of the study include limited data due to the number of participants and the convenience of the sample. The small sample size may not allow the information to be generalizable to other educational settings. Greater strength can be applied to the findings when similar data is collected from larger studies. Most of the participants were females which may post gender-mixed view bias. Assessment of learning gains and academic outcomes from student originated project is a combination of attitudes, personal and professional experiences that affects data collection.

\section{ACKNOWLEDGEMENTS}

The researchers would like to extend their sincere gratitude to Mrs. Maria Theresa I. Canonigo who gave time and effort in correcting the grammar of the study likewise to Year I - Bachelor of Science in Nursing students of Academic Year 2015-2016 at Rustaq Nursing Institute for their active participation as the respondents of the study.

\section{CONFlicts OF InTEREST Disclosure}

The authors declare that there is no conflict of interest.

\section{REFERENCES}

[1] American Association of College of Nursing. The Impact of Education on Nursing Practice. 2015. Available from: http://www . aacn .nche.edu

[2] Jeffries PR. The Evolving Health Care System: The Need for Nursing Education Reform. Journal of Professional Nursing. 2015; 31(6): 441 443. PMid:26653037 https://doi.org/10.1016/j.profnurs .2015 .10 .012

[3] Robinson K. The Element: How Finding your Passion Changes Everything. Penguin Books Reprint Edition. 2009.

[4] Boss S. Project-based learning: A Short History. George Lucas Educational Foundation. 2011.

[5] Katja B, Arnim W, Charles LR. Real-world learning opportunities in sustainability: from classroom into the real-world. International Journal of Sustainability in Higher Education. 2010; 11(4): 308-324 https://doi .org/10.1108/14676371011077540

[6] Lee HJ, Cheolil L. Peer Evaluation in Blended Team Project-based learning: What do students find important? Journal of Education Technology and Society. 2012; 15(4): 214-224.

[7] Berliner G. Educational psychology. 5th ed. Princeton, New Jeysey: Houghton Mifflin Company. 2015. Available from: http: //www.edpsyinteractive.org/papers/modeltech.html
[8] Joseph FJ. The Value of Student-Originated and student-Run Ecology Projects. The American Biology Teacher. 1991; 53(3): 170-171. https://doi.org/10.2307/4449253

[9] Ulseth R. Self-Directed Learning in PBL. Aalborg Universitetsforlag. Ph.d.-serien for Det Teknisk-Naturvidens-kabelige Fakultet, Aaborg Universitet. 2016.

[10] Thomas J. A Review of Research on Project-Based Learning. Autodesk Foundation, California. 2000. Available from: http://www . bie.org/index.php/site/RE/pbl_research/29

[11] Project-Based Learning Handbook. PBL-online. 2015. Available from: http://www.bie.org/pbl/pblhandbook/index.php

[12] Gordon R. Balancing Real-World Problems with Real-World Results. Phi-Delta Kappan. 1998; 79(5): 390-93.

[13] Sahin A. A Practice-based Model of Stem Teaching. Stem Students on the Stage(SOS). Rotterdam the Netherlands. Sense Publisher 2011.

[14] Joan S, Andrew HS. Problem-Based Learning as a Classroom Solutions. Educational Leadership. Strategies for Success. 1994; 52(3): 54-57.

[15] Boaler J. Mathematics for the Moment or the Millennium? Educational Week. 2009; 18(29): 30. 